\title{
CORPO INFANTIL, ARTEFATOS CULTURAIS E O PROCESSO DE PEDOFILIZAÇÃO SOCIAL
}

\author{
Raimundo José Pereira da Silva ${ }^{\mathrm{i}}$ \\ Jackson Ronie Sá-Silva ${ }^{\text {ii }}$
}

\begin{abstract}
Resumo: O artigo problematiza o tema da erotização dos corpos infantis na sociedade contemporânea a partir de pesquisa bibliográfica. A ideia de infância vem sofrendo modificações significativas ao longo da história e os artefatos culturais são materialidades privilegiadas nesse processo de discursar sobre o corpo da criança. A discussão está assentada nas proposições teórico-metodológicas dos Estudos Culturais em Educação na vertente pósestruturalista. Apresenta-se o conceito de pedofilização social para explicar os processos complexos da exposição mídiática dos corpos infantis. Professores e professoras precisam se apropriar dessas discussões para que compreendam a complexidade cultural que opera nos corpos infantis e os adultizam, tornando-os objetos de diferentes desejos e consumo.
\end{abstract}

Palavra-chave: Corpo infantil; Infância; Erotização.

\section{CUERPO INFANTIL, ARTEFACTOS CULTURALES Y EL PROCESO DE PEDOFILIZACIÓN SOCIAL}

Resumen: El artículo discute el tema de la erotización de los cuerpos infantiles en la sociedad contemporánea a partir de la investigación bibliográfica. La idea infancia viene sufriendo cambios significativos a lo largo de la historia y los artefactos culturales son materialidades privilegiadas en este proceso de discursar sobre el cuerpo del niño. La discusión está basada en las proposiciones teórico-metodológicas de los Estudios Culturales en Educación en su aspecto posestructuralista. El concepto de pedofilización social se presenta para explicar los procesos complejos de la exposición mediática de los cuerpos de los niños y sus efectos educativos. Los profesores deben apropiarse de estas discusiones para que comprendan la complejidad cultural que opera en los cuerpos infantiles y adultizan, los convierten en objetos de diferentes deseos y consumo.

Palabras-clave: Cuerpo infantil; Infancia; Erotización.

\section{Considerações iniciais...}

"O corpo também escapa: ele é maleável; ele pode falar mil línguas, ter muitos significados [...] ele engana e ilude" (LOURO, 2000, p. 63).

Ao longo da história o corpo humano foi sendo objeto de análise e pesquisa das mais diferentes ciências: medicina, psicologia, antropologia, pedagogia, dentre outros. A (c) (i) (2)

2019 Silva; Silva. Este é um artigo de acesso aberto distribuído sob os termos da Licença Creative Commons Atribuição Não Comercial-Compartilha Igual (CC BY-NC-4.0), que permite uso, distribuição e reprodução para fins não comercias, com a citação dos autores e da fonte original e sob a mesma licença. 
história do corpo, como explicita a historiadora Denize Bernuzzi de Sant'Anna (2006), é infindável, repleta de questões sociais e culturais. O corpo não ocupa apenas o plano biológico, mas uma relação "biocultural". Por isso, "realizar uma história do corpo é um trabalho tão vasto e arriscado quanto aquele de escrever uma história da vida" (SANT'ANNA, 2006, p.3).

O antropólogo francês David Le Breton, na obra a Sociologia do Corpo, afirma que o corpo existe na totalidade dos elementos que o compõem graças ao efeito conjugado da educação recebida e das identificações que levaram o ator a assimilar os comportamentos de seu círculo social (LE BRETON, 2007, p.9). Desse modo, o corpo é objeto cultural produzido na cultura e para cultura, e por isso [...] implica entendê-lo não apenas como um dado natural e biológico, mas, sobretudo, como produto de um intrínseco inter-relacionamento entre natureza e cultura (GOELLNER, 2010, p.73).

A história do corpo é uma narrativa interessante e instigadora. Considera-se que o corpo [...] não cessa de ser descoberto, é preciso não perder de vista a provisoriedade de cada conhecimento produzido a seu respeito: constantemente redescoberto, nunca, porém, completamente revelado (SANT'ANNA, 2000a, p.237). Isso mostra que os sentidos que damos aos nossos corpos e as possibilidades sexuais, tornam-se de fato, uma parte vital de nossa formação individual, sejam quais forem as explicações sociais (WEEKS, 2016, p.48).

Nesse sentido, deve-se salientar que o ato de adentrarmos a história do corpo tem sido uma tarefa árdua, no sentido de problematizar os significados que fizeram (e fazem) dele um artefato histórico. Assim, entendemos que o corpo é uma construção cultural sobre a qual são conferidas diferentes marcas em diferentes tempos, espaços, conjecturas econômicas, grupos sociais, étnicos etc. (GOELLNER, 2010, p.73).

Nesse contexto, a Internet e as redes sociais têm ocupado espaços de maior visibilidade performática do corpo, aproximando as pessoas de diversas idades, inclusive as crianças, que passam a ser consideradas consumidoras em potencial, devido à ampla comercialização de produtos voltados para a infância. De acordo com Beck, essa proposta de consumo na infância se posiciona como uma das formas de produzir, desde pequenos, os consumidores do presente e do futuro, incitando-os a constituir suas identidades pelas malhas do consumo (BECK, 2017 p.41).

Outra questão que tem chamado à atenção nesses últimos anos diz respeito à exposição erótica e sexual de crianças na mídia brasileira: [...] é possível verificar que a representação de pureza e ingenuidade, suscitada pelas imagens infantis veiculadas pela Revista Interinstitucional Artes de Educar. Rio de Janeiro, V. 5, N.3-pág. 612-627 set-dez de 2019: "Educação: Corpo em movimento." - DOI: 10.12957/riae.2019.45792 
mídia, tem sido substituída por outras extremamente 'erotizadas', principalmente em relação às meninas (FELIPE; GUIZZO, 2003, p.120).

É importante compreender os efeitos desse processo de investimento a partir do embelezamento infantil no qual a criança é tida como objeto de desejo e erotização. Os corpos infantis passam a ser compreendidos como objeto de investimento que se amplia na perspectiva do consumismo e embelezamento. Compreender outras dimensões do corpo, sem desconsiderar sua natureza biológica e reprodutivista, tem sido um desafio constante e, mais ainda, no espaço educacional. Seria possível ampliar a discussão sobre o corpo infantil para além do viés biológico? Que outras possibilidades podem ser desenvolvidas para tematizar o corpo infantil?

Através dos Estudos Culturais em Educação é que buscamos problematizar discussões que mobilizem outros olhares para perceber as sutis estratégias da complexa produção cultural do corpo infantil, visando mostrar que, na sociedade contemporânea, a valorização do consumo a partir de artefatos culturais e midiáticos tem provocado efeitos significativos na infância e na educação infantil.

Os Estudos Culturais (EC) surgiram em meados do século XX. Desde então, esse campo teórico tem direcionado diferentes pesquisas relacionadas à educação, buscando dar ênfase à dimensão cultural que é produzida nos diferentes espaços sociais. Em outras palavras, sua preocupação está intimamente relacionada à linguagem, às construções simbólicas, aos rituais, à história, à memória etc.. Os EC são utilizados como uma ferramenta de análise das contradições sociais, políticas e culturais, bem como na construção de um contra-discurso a partir da elaboração de outros significados.

Nessa perspectiva, segundo as autoras Costa, Silveira e Sommer, (2003, p.43), os EC são um campo de pensamento muito pluralizado e se diversificam segundo seus espaços teóricos de produção. As autoras tecem ainda outros encaminhamentos sobre esse campo, mostrando que "eles são muitas coisas ao mesmo tempo, [...] tanto as velhas e consagradas disciplinas como os movimentos políticos, práticas acadêmicas e modos de investigação tais como o marxismo, o pós-colonialismo, o feminismo, o pós-estruturalismo”.

\section{Ideias sobre o corpo e sua produção cultural}

Os corpos são educados constantemente por práticas sociais que regulam, disciplinam, normatizam os sujeitos. O discurso binário e biológico enfatiza que homens e Revista Interinstitucional Artes de Educar. Rio de Janeiro, V. 5, N.3-pág. 612-627 set-dez de 2019: "Educação: Corpo em movimento." - DOI: 10.12957/riae.2019.45792 


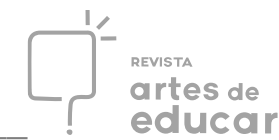

mulheres se constroem masculinos e femininos através das diferenças corporais, anatômicas e genitais. No entanto, não se trata de negar a materialidade dos corpos, mas sim de assumir que é no interior da cultura e de uma cultura específica que características materiais adquirem significados (LOURO, 2008, p.22). Assim, os significados que damos aos nossos corpos são permeados de construções culturais. Não podendo negar que a inscrição dos gêneros - masculino ou feminino - é feita, sempre, no contexto de uma determinada cultura e, portanto, com as marcas dessa cultura (LOURO, 2016, p.11).

Para ampliar essa análise sobre a construção histórica e cultural do corpo, Goellner (2013, p.35) enfatiza que a exaltação ao corpo como conhecemos hoje tem seu início no final do século XVIII e se intensifica no século XIX porque nesse tempo, o corpo adquire relevância nas relações que se estabelecem entre os indivíduos. Nesse mesmo período, gestase uma moral das aparências que faz convergir o que se aparenta ser com o que, efetivamente, se é.

Assim, Sant'Anna (2000b) também explicita que o corpo faz parte de um processo histórico, e por isso, cada civilização constrói sua forma de ver e representar o corpo, assim como foi desde o Período Neolítico com a ornamentação e tatuagens, depois com a utilização de produtos cosméticos e de cirurgias estéticas, até os dias atuais.

Para os gregos a educação do corpo era um importante eixo norteador no desenvolvimento da sexualidade humana, fonte de aprendizagem e conhecimento. Segundo Foucault, na Grécia a verdade e o sexo se ligavam na forma da pedagogia, pela transmissão corpo a corpo de um saber precioso; o sexo servia como um suporte às iniciações do conhecimento (FOUCAULT, 2017, p.69).

Foucault (2017) fez uma análise crítica sobre a sexualidade e apresentou dois polos discursivos que resultou em visões diferenciadas sobre o corpo, sendo a primeira centrada na "anátomo-política do corpo humano", e a segunda em uma "bio-política da população". Tais discursos sobre o corpo tinham a função de intensificar o discurso da sexualidade no sentido que quanto mais se falava sobre a sexualidade, mais poder se poderia ter sobre os sujeitos e suas vidas. E para isso, os dispositivos veiculadores de tais discursos são essenciais na forma de controle e prolongamento da vida humana.

É nesse discurso sobre o sexo que se articulou o discurso sobre o corpo, pois falar do corpo era também falar do sexo, e ambos funcionam como táticas de controle, de regulação da sexualidade. Assim, é possível perceber que, ao longo da história, os discursos sobre a sexualidade se constituíram como [...] um corpo de conhecimento que modela as formas Revista Interinstitucional Artes de Educar. Rio de Janeiro, V. 5, N.3-pág. 612-627 set-dez de 2019: “Educação: Corpo em movimento." - DOI: 10.12957/riae.2019.45792 


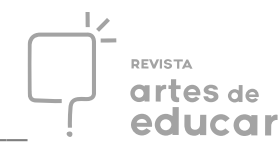

como pensamos e conhecemos o corpo. Ela não pode ser caracterizada como um "regime de silêncio", mas, ao contrário, como um constante [...] incitamento ao discurso sobre o sexo (WEEKS, 2016, p.50).

A categoria corpo e a categoria sexualidade revelam a centralidade na construção humana e cultural, impregnadas de verdades e saberes. Discursos médicos, pedagógicos, psicanalíticos, jurídicos, e referentes a outras ciências tentam, a todo instante, impetrar um discurso de verdade que valida o comportamento dos corpos e suas posturas sexuais como normais ou anormais.

Cada acontecimento histórico ocorrido na sociedade está diretamente ligado ao corpo, pois os corpos são significados pela cultura e, continuamente, por ela alterados (LOURO, 2016, p.14) porque estão em constante processo de construção social e cultural. Nessa perspectiva, concordamos que:

O corpo não é apenas um corpo. É também o seu entorno. Mais do que um conjunto de músculos, ossos, vísceras, reflexos e sensações, o corpo é também a roupa e os assessórios que o adornam, as intervenções que nele se operam, a imagem que dele se produz, as máquinas que nele se acoplam, os sentidos que nele se incorporam, os silêncios que por ele falam, os vestígios que nele se exibem, a educação de seus gestos...enfim, é um sem limite de possibilidades sempre reinventadas e a serem descobertas (GOELLNER, 2013, p.30).

Somos atraídos pelos desejos e práticas sociais que buscam qualificar, quantificar os sujeitos em todos os sentidos. Existem artefatos culturais acionando o corpo como objeto de consumo, desejo e descarte, e por essa razão, podemos pensar no corpo como algo que se produz historicamente, o que equivale dizer que o nosso corpo só pode ser produto do nosso tempo, seja do que dele conhecemos, seja do que ainda está por vir (GOELLNER 2013, p.41).

O consumo vem produzindo corpos úteis, os quais precisam estar moldados para conquistar, ser incluídos, desejados, possuídos, amados e investidos. É interessante notar como essas representações do corpo têm afetado as crianças, provocando uma ruptura entre a fase infantil e adulta.

A relação corpo-mercadoria é resultado do avanço acelerado das mídias e das redes sociais que vem contribuindo para a exposição frequente dos corpos adultos e infantis em meio à publicidade. Observamos que esse impacto tem influenciado meninos e meninas a 
se comportarem de forma adultizada, tendo acesso a espaços de consumo midiáticos e digitais inapropriados para sua idade, como: Youtube, Instagran e Facebook.

Tais artefatos culturais e midiáticos acabam desempenhando uma atividade educativa na vida das crianças, construindo relações de cuidado com o corpo e com a aparência física a partir de um embelezamento que se manifesta em roupas, brinquedos, programas de TV e demais espaços da mídia atual.

É preciso problematizar a exposição erótica das crianças, e principalmente das meninas, como um corpo desejável. Mesmo com o surgimento de diversas formas jurídicas visando à proteção da criança e do adolescente, é crescente o número de crianças vítimas da violência sexual e da pedofilia. As propagandas de moda e cosméticos, em sua maioria, incitam a moldar esse corpo infantil segundo uma relação corpo-produto, contribuindo para borramentos de fronteiras na infância, resultando, assim, em um processo de adultização da criança (FELIPE, 2013).

Algumas questões aparecem: que infância é essa? A que pedagogia as crianças estão sendo sujeitadas no processo complexo de consumo do capital na contemporaneidade?

[...] se a pedagogia teve que inventar uma criança e uma infância para o projeto moderno civilizador, certamente as instâncias midiáticas reinventam uma criança para o consumo de seus produtos: as crianças não aparecem mais como inocentes e, principalmente, imaturas. Por exemplo, nas propagandas publicitárias os meninos entendem tudo de computadores, vídeo games e os sistemas digitais, e as meninas aparecem como pequenas mulheres provocantes, preocupadas com seus corpos, desfilando, fazendo poses e demonstrando que sabem bem o que querem no momento das compras (CÂMARA, 2007, p. 52).

A pedagogia que a mídia exerce sobre os corpos infantis consiste em transformar as crianças em um modelo ideal de consumidor, tendo pleno exercício de consumo e liberdade para realizar suas vontades e desejos. Os jogos virtuais, por exemplo, têm assumido o papel do brinquedo numa forma mais atualizada para essa infância contemporânea, o que provoca questionamentos sérios quanto ao uso desses meios digitais pelas crianças.

Para Felipe (2006, p.207) não se trata aqui, porém, de demonizar as novas tecnologias e, com isso, anunciar um pânico moral, tentando resgatar uma infância com aura de pureza e ingenuidade que ficou para trás [...], mas em problematizar os efeitos que essa influência tecnológica tem provocado nas crianças para, assim, melhor repensar a ideia de infância que está sendo produzida diante do processo paradoxal que versa pela sua proteção. 


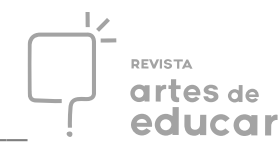

Com o surgimento dos veículos de comunicação de massa (TV, cinema, internet, redes sociais etc.) as crianças adquiriram novos hábitos relacionados ao consumo, e encontraram nesses espaços de interação e diversão digital, símbolos, imagens, músicas e representações sobre corpo, gênero e sexualidade.

Mas é preciso se perguntar: quais os possíveis riscos que a internet representa para as crianças e o que elas têm aprendido com tantas informações?

\section{Pensar os corpos infantis a partir dos artefatos culturais e o processo de pedofilização}

Não são poucas as estratégias de investimento nos corpos infantis nessa contemporaneidade. Desde as décadas de 1980, a questão da erotização já era problematizada em razão dos comportamentos e estilos das apresentadoras que passaram a preconizar programas infantis. Mara Maravilha, Angélica, Mariana são alguns dos exemplos; porém a Xuxa é o mais significativo deles (GUIZZO; BECK, 2011, p.18-19).

Assim, mesmo que essas apresentadoras e seus programas de televisão não estejam mais no ar, [...] ainda são com grande frequência apontados e criticados como negativos às crianças, pela falta de teor educativo que apresentavam e pelo estímulo às práticas de embelezamento, à erotização e à sensualidade precoces [...] (BECK; GUIZZO, 2016, p.19). No entanto esses programas registraram seu legado abrindo outras formas de entretenimento infantil que têm atingido consideravelmente as crianças em diferentes aspectos sociais na mídia brasileira.

É comum observarmos crianças e, neste caso principalmente meninas, em ensaios fotográficos e em programas de televisão, sendo cortejadas como meninas educadas, sensíveis e atraentes. A criança não apenas ganhou destaque em espaços televisivos, como também em propagandas de cosméticos e concursos de misses e mister mirins. A importância do corpo infantil, em especial do corpo infantil feminino, tem se diversificado através de acessórios, maquiagens, sapatos, batons, entre outros produtos.

Nesse sentido, a criança já nasce numa cultura consumista e cresce segundo os padrões de beleza estabelecidos pela sociedade através das mídias que estimulam a crescente valorização dos corpos para o mercado de consumo. Deve-se salientar também que a mídia a todo instante vem criando padrões de beleza para atender as expectativas de investimento e 
produção corporal de forma supérflua, buscando expor ainda mais as crianças em situações adultizadas.

O crescimento capitalista e a ampliação do comércio internacional têm refletido diretamente na economia mundial e vêm impulsionando diferentes setores de produção da economia brasileira. A ênfase na produção midiática e cosmética tem sido um dos pontos fulcrais nesse segmento mercadológico e logístico. $\mathrm{O}$ investimento em campanhas publicitárias, revistas de moda e beleza, programas de televisão, perfumaria, jogos eletrônicos, sites de relacionamentos ganhou muita força na atualidade, ampliando outras perspectivas de investimento no corpo.

Aliado a esse aspecto de expansão do mercado e do crescimento industrial de produtos voltados para a beleza, tratamento estético corporal e de acessórios para o corpo, acompanhamos também tal crescimento demarcado pela constante tentativa de padronização dos corpos, sejam eles masculinos ou femininos. A visibilidade que as propagandas estéticas têm favorecido aos corpos infantis tem sido imensa.

Para as autoras Beck e Guizzo (2016), o apelo exercido sobre os corpos infantis - principalmente os corpos infantis femininos- tem acarretado um crescimento significativo no mercado de consumo, pois:

[...] no Brasil foi mais fortemente a partir do início dos anos 1980 que o mercado investiu mais intensamente nas crianças como consumidoras em potencial. Foi nesse período que programas televisivos infantis passaram a ser comandados por jovens e belas apresentadoras que tinham, dentre outras tarefas, a incumbência de promover a venda de variados produtos dentre os quais podem ser destacados: sapatos, roupas, produtos de beleza, etc. Nessa mesma época, grandes empresas como Avon e Nívea (e um pouco mais tarde O Boticário e Natura) passaram a produzir cosméticos específicos para bebês e crianças que até hoje estão no mercado (GUIZZO; BECK, 2011, p.33).

A inserção das crianças em espaços de consumo tem apresentado consequências sérias à sociedade no que tange o crescimento e o desenvolvimento infantil. As crianças estão cada vez mais se distanciando do corpo infantil ingênuo e paparicado, e buscando alternativas de viver a infância numa perspectiva adultizada. É importante se perguntar: o que tem levado as crianças a se comportarem dessa forma? Porque existem em nosso tempo tantas crianças que estão transgredindo a infância, a qual é vista como uma fase tão importante no desenvolvimento humano? 
A adultização das crianças neste século tem se tornado um problema sério ao qual não tem sido dada a devida atenção. Assim,

Tal processo, que chamamos aqui de "pedofilização" da sociedade, merece ser examinado com maior atenção, na medida em que as crianças têm sido alvo de um forte apelo comercial, sendo descobertas como consumidoras e, ao mesmo tempo, como objetos a serem consumidos (FELIPE; GUIZZO, 2003, p.120).

Diante deste cenário complexo sobre a erotização dos corpos infantis, Felipe (2006) questiona: afinal, quem é mesmo o pedófílo? A autora tem instigado a pensar o processo de pedofilia para além do sujeito pedófilo, mostrando que não apenas o pedofílo deve ser visto como culpado, que também existem outras questões sociais e culturais ligadas a ele nesta mesma ação pedofílica. Em outras palavras: $\mathrm{O}$ que estaria aguçando o olhar do pedófilo para as criancinhas?

O conceito de pedofilização desenvolvido por Felipe (2006) nos ajuda a pensar nos modelos de infância que atualmente estão sendo construídos e pensados para a lógica capitalista e de consumo, pois as crianças ao mesmo tempo em que são vulneráveis à violência sexual e amparadas pelas leis, estão sendo expostas em diferentes veículos de comunicação como desejáveis, aguçando ainda mais, nos adultos, o interesse sexual por elas. As meninas são expostas em modos eróticos e sensuais, representadas por uma fragilidade atribuindo à sexualidade feminina a ideia de uma criança indefesa e ao mesmo tempo sedutora e atraente.

Assim, conforme enfatiza Felipe (2006, p.220-221), esse processo de embelezamento, fetiche e adultização da criança, nos leva a problematizar outra dimensão do conceito de pedofilização, como por exemplo:

[...] em revistas dirigidas ao público masculino heterossexual, na medida em que as jovens e belas modelos que aparecem em muitos dos ensaios sensuais e pornográficos veiculados por essas revistas, utilizam-se de elementos do mundo infantil, como bichinhos de pelúcia, roupas de colegial, etc. A própria aparência das modelos (mesmo sendo maiores de idade), remete-nos às feições de meninas pré-adolescentes, associada a essa mistura de ingenuidade e sedução.

O fetiche funciona como algo sedutor, envolvido por gestualidade e delicadezas provocantes e sensuais. Esses fetiches eróticos são representados geralmente por objetos, roupas que lembram a infância, os quais são utilizados com frequência por modelos e Revista Interinstitucional Artes de Educar. Rio de Janeiro, V. 5, N.3- pág. 612-627 set-dez de 2019: “Educação: Corpo em movimento." - DOI: 10.12957/riae.2019.45792 
profissionais do ramo pornográfico, incitando homens e mulheres a consumir produtos e serviços eróticos com símbolos e significados infantis.

Por isso, o conceito de pedofilização chama atenção para as formas como a sociedade vem construindo uma ideia de crianças protegidas, ao mesmo tempo em que são sexualizadas pelos diferentes artefatos culturais, sendo eles: TV, cinema, música, jornais, revistas, propaganda, outdoors, brinquedos, e outros.

É importante ressaltar ainda que, a Constituição Federal de 1988 enfatiza que é dever da família a proteção da criança e do adolescente, bem como o Estatuto da Criança e do Adolescente (ECA) de 1990, que endossa essa mesma compreensão e ainda prevê punições a quem cometer qualquer dano à criança e ao adolescente, principalmente quando relacionados a casos de violência sexual.

Entendemos que a criança precisa de cuidado, carinho, atenção a qualquer ação que viole seus direitos. No entanto, são vastos os motivos que têm levado a criança a viver a infância sendo exposta a situações que acarretam danos a sua integridade física, social e psicológica.

Vivemos em uma sociedade que privilegia a vida em função do consumo de obter um corpo perfeito em nome de um status social. Por isso, muitas vezes a ideia de um corpo perfeito é confundido com saúde. Ou seja, ser gordo é ser doente? Essa classificação de que apenas um corpo magro pode ser considerado um corpo saudável, causa uma estranha generalização em relação a outras culturas. Cada cultura tem sua forma de ver e desejar o corpo, e portanto:

cada tentativa feita para conhecer o funcionamento do corpo, incluindo os seus significados biológicos e culturais, é desencadeadora de esclarecimentos e de dúvidas inusitadas a seu respeito. Da medicina dos humores à biotecnologia contemporânea, passando pela invenção de regimes, cirurgias, cosméticos e técnicas disciplinares, o conhecimento do corpo é por excelência histórico, relacionado aos receios e sonhos de cada época, cultura e grupo social (SANT'ANNA, 2000a, p.237).

Existem culturas que preferem um corpo gordo ao invés de magro, assim como o contrário, ou mesmo a valorização de ambos os corpos, sem nenhuma diferenciação. Mas o que significa, nessa perspectiva, acreditar que um corpo magro simboliza saúde e padrão de beleza? Não podemos esquecer de que existe em nossa sociedade um problema sério relacionado a essa questão: a anorexia. Existe uma produção cultural de homens, mulheres e crianças anoréxicas.

Revista Interinstitucional Artes de Educar. Rio de Janeiro, V. 5, N.3- pág. 612-627 set-dez de 2019: "Educação: Corpo em movimento." - DOI: 10.12957/riae.2019.45792 
O empreendimento cultural e de consumo do corpo ocorre de forma minuciosa sem que as pessoas se deem conta dos riscos que esse exagero pode causar à saúde, além de outras consequências sociais: um alerta é importante [...] nos últimos anos a explosão da indústria da medicina estética e da beleza e tal mercado vem se mostrando potente e rentável muito pela associação que tem se produzido entre beleza e saúde (BECK; GUIZZO, 2016, p.7), e o Brasil tem investido bastante nesse segmento mercadológico e logístico na produção da cultural visual do corpo.

A crescente abertura de espaços estéticos e academias de musculação e ginástica tem ganhado bastante visibilidade. Nessa questão, o cuidado com o corpo e a beleza não está atingindo apenas homens e mulheres, mas também às crianças. Meninos e meninas que estão acompanhando esse segmento de produção corporal, por meio de um apelo comercial midiático. Tal impacto tem provocado efeitos drásticos na vida infantil mostrando às crianças que, para serem aceitas na sociedade, precisam estar belas e atraentes.

Segundo a autora Fischer (1997, p.61), a mídia, pode ser considerada não apenas como [...] veiculadora, mas também como produtora de saberes e formas especializadas de comunicar e de produzir sujeitos, assumindo nesse sentido uma função nitidamente pedagógica, pois ela não apenas educa como também posiciona papeis sociais, gênero e sexualidade, e, portanto, funciona como [...] espaço educativo onde imagens de crianças, adolescentes, mulheres e homens podem ser consumidas, tendo como referencial modelos social, econômico e cultural hegemônicos (SABAT, 2013, p.152-153).

A mídia investe muito em propagandas visando atrair crianças, jovens e adultos para que estejam cada vez mais embelezados/as. Nessa procura desenfreada pela "juvenilização" do corpo e da vida, as crianças aprendem, no dia a dia, várias formas de melhorar sua aparência física. Por isso, a inserção de crianças em espaços de beleza tem sido cada vez maior. E o mesmo vem ocorrendo com os adultos que fazem o possível para parecerem jovens e atraentes, recorrendo a cirurgias estéticas e outros meios para garantir a "boa" aparência física e juvenil.

Pensar no corpo infantil masculino e feminino é compreender que os corpos não são universais, mas culturais, dado que o corpo é porque é provisório, mutável, líquido, suscetível a uma infinidade de intervenções, sejam elas científica, tecnológica, discursiva e cultural. Os corpos são veículos de comunicação, cultura e práticas sociais endereçadas na constituição dos sujeitos. Por isso, o corpo infantil desde cedo passa pelo processo de 
escolarização, começando desde a infância, na educação infantil, e atravessado pelos meios midiáticos que pedagogizam modos de ser e estar criança na sociedade.

A mídia, ao utilizar conteúdos com sentidos sexuais e de sedução, reforça ainda mais o desejo sexual dos pedófilos por esse corpo adultizado. Casos de pedofilia e violência sexual não deixam de ser constantemente denunciados e a sociedade parece não estar atenta cuidadosamente a questões sérias como a erotização dos corpos das crianças, quando estas são expostas nas mídias em poses sensuais.

De acordo com Guizzo (2009, p.99), o culto ao corpo infantil vem se alongando muito, pois "a valorização do potencial de consumo dessa faixa etária tem se caracterizado como uma tendência global". Por isso, a concepção deste século sobre infância tem revelado verdadeiras lacunas para se pensar quais modelos de infância e corpos infantis estão sendo produzidos.

É importante ressaltar que:

Ao disponibilizarmos determinadas imagens das menininhas não estamos construindo apenas um modo de representá-las direcionadas somente para os homens, mas também para as próprias meninas e adolescentes, que vão sendo subjetivadas por essas pedagogias da sexualidade. Elas aprendem que para serem desejadas, amadas, valorizadas, precisam se comportar de determinada forma, que o poder das mulheres está constantemente referido e atrelado à sua capacidade de sedução, que passa por um belo corpo e a utilização deste como performático (FELIPE, 2006, p.221-222).

A imagem de uma criança erotizada não é vista apenas por quem a deseja, mas pela própria menina por entender que aquele corpo vestido de roupas e acessórios anuncia um novo segmento da beleza infantil.

Isso também não se aplica apenas ao corpo humano, mas aos corpos-brinquedos, corpos-músicas, corpos-roupas, corpos-discursos, enfim, a tudo o que toma a proporção de moldar e educar a criança. Como exemplo, pode-se apontar a boneca Barbie que além de loira e branca, é também negra, morena, baiana. É também estilosa, atraente, performática, sedutora e erótica. Necessário se perguntar: quais os efeitos da "pedagogia Barbie" nas crianças? O problema não está apenas no brinquedo Barbie, mas nos discursos que estão sendo acionados pela sua linguagem. 


\section{Algumas considerações finais}

Problematizamos ao longo desse ensaio teórico o quanto o corpo é alvo de constantes apelos econômicos e socioculturais, que por meio de uma lógica de consumo, produzem imperativos de beleza e juvenização dos corpos. Através das teorizações realizadas, foi possível argumentar sobre a produção cultural midiática do corpo infantil, e também tentar compreender os impactos da exposição erotizada e sensualista de crianças nos meios publicitários e nas mídias atuais, sobre a vida das mesmas.

Devemo-nos contrapor a uma ideia discursiva que tende a acelerar o crescimento da criança transformando-a em um sujeito adultizado. Entendemos que pensar a infância e a educação da criança nesse século representa um desafio no campo da Educação e requer compreensões ampliadas sobre a produção cultural dos corpos infantis: olhar com mais acurácia para o processo de erotização e adultização infantil que tem se desdobrado em escala exponencial e descontrolada.

A escola é o espaço de vivência da pluralidade e deve ser espaço também da igualdade e respeito ao gênero e à sexualidade. Tematizar essa discussão na escola envolve uma compreensão conceitual, sistemática que, de maneira dialógica, permita abordar tais temas sensíveis no espaço escolar. Afinal, qual seria o papel da escola no enfrentamento da violência sexual infantil, pedofilia, discriminação de gênero e sexualidade, senão através do diálogo? É importante que os docentes da educação infantil estejam atentos às novas configurações de infância, compreendendo as sutilezas do funcionamento dos mecanismos de produção das desigualdades sociais, culturais, de gênero e sexualidade.

Desta forma, precisamos nos apropriar teoricamente do conceito de pedofilização social, desenvolvido e teorizado pela professora e pesquisadora das relações de gênero e sexualidade, Jane Felipe (2006). Compreendê-lo pelas lentes pós-estruturalistas é meio de operacionalizar criticamente sobre o papel da educação desconstrucionista: ajuda a compreender mais amplamente as desigualdades sociais, as desigualdades sexuais, as questões complexas que envolvem o conceito de gênero e etnia, e de qualquer outra forma de violência que se manifeste contrariamente à educação ética e cidadã.

A perspectiva desconstrucionista trabalha com o processo de ressignificação das práticas de produção cultural, buscando entender que um espaço cultural como a escola é repleto de discursos, ideias e representações sobre masculinidade e feminilidade. O ferramental desconstrucionista na educação busca desmantelar o que foi dado e consagrado Revista Interinstitucional Artes de Educar. Rio de Janeiro, V. 5, N.3- pág. 612-627 set-dez de 2019: "Educação: Corpo em movimento." - DOI: 10.12957/riae.2019.45792 


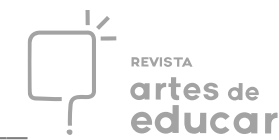

como natural, único, estável. Assim, sugere-se que a referida temática seja pauta de uma educação sexual hipercrítica e desconstrucionista para que se desenvolva a alteridade e o acolhimento cidadão dos sujeitos sociais de forma contextualizada e não-sexista.

É nesse sentido que precisamos estar atentos para combater a violência sexual infantil na sociedade e entender que tal prática é uma tarefa que compete a todos/as, de forma que na escola seja um dos meios que oportunize essa ação. Para que essa temática seja inserida nas escolas, faz-se necessária uma formação docente hipercrítica que reverbere na educação básica - desde a educação infantil- a ideia cidadã de alteridade e respeito ao outro.

\section{REFERENNCIAS}

BECK, D. Q.; GUIZZO, B. S. Corpo, mídia e embelezamento: identidades de gênero na infância. In: Perspectivas em Diálogo: Revista de Educação e Sociedade, Naviraí, v.3, n.6, p. 3-24, jul./dez. 2016.

BECK, D. Q. Mídia e consumo: pedagogias culturais de investimento na infância. In: BECK D. Q.; ESPERANÇA, J. A. (org.). Infâncias em foco: mídia, consumo e artefatos da cultura contemporânea. Rio Grande: Ed. da FURG, 2017.

BRASIL. Constituição da República Federal do Brasil. Brasília, DF: Senado Federal, 1988.

BRASIL. Lei n⿳0 8069/90, dispõe sobre o Estatuto da Criança e do Adolescente. Brasília, DF, 1990.

CÂMARA, A. P. Masculinidade heterossexual e pedofilização: Apontamentos iniciais para um debate. Revista Ártemis. Paraíba, v. 6, p. 49-57, 2007.

COSTA. M. V.; SILVEIRA, R. H.; SOMMER, L. H. Estudos Culturais em educação e pedagogia. Revista Brasileira de Educação, n. 23, maio/ jul./ ago. 2003.

FELIPE, J. Afinal, quem é mesmo pedófilo? Cadernos Pagu, Campinas: Unicamp, n. 26, p. 201- 223, jan./jun. 2006.

FELIPE, J. Erotização dos corpos infantis. In: LOURO, G.L. et al. (org.) Corpo, gênero e sexualidade: um debate contemporâneo na educação. 9.ed. Petrópolis/RJ: Vozes, 2013.

FELIPE, J.; GUIZZO, B. S. Erotização dos corpos infantis na sociedade do consumo. Revista Pro-Posições, v. 14, n.3, set./dez. p. 119-130, 2003.

FISCHER, R. M. B.O Estatuto pedagógico da mídia: questões de análise. Educação \& Realidade, Porto Alegre, v. 22 n. 2, jul/dez. 1997. 
FOUCAULT, M. História da sexualidade I: a vontade de saber. Tradução Maria Thereza da Costa Albuquerque e J. A. Guilhon Albuquerque. 5. ed. Rio de Janeiro/São Paulo: Paz \& Terra, 2017.

GOELLNER, S. V. A Educação dos corpos, dos gêneros e das sexualidades e o reconhecimento da diversidade. Cadernos de FormaçãoRBCE, v. 1, n. 2, p. 71-83, mar. 2010.

GOELLNER, S. V. A produção cultural do corpo. In: LOURO, G. L.; FELIPE, J.; GOELLNER, S. V. (org.). Corpo, gênero e sexualidade: um debate contemporâneo na educação. 9. ed. Petrópolis: Vozes, 2013.

GUIZZO, B. S. Infância contemporânea, consumo e moda. Textura, n. 19-20, p. 96-112, 2009.

GUIZZO, B. S.; BECK, D. Q.; Corpo, gênero, erotização e embelezamento na infância.Textura, n.24, p. 16-36 jul./dez, 2011.

LE BRETON, D. A sociologia do corpo. 2. ed. Petrópolis, RJ: Vozes, 2007.

LOURO, G. L. Pedagogias da sexualidade. In: LOURO, G. L. (org.). O corpo educado: pedagogias da sexualidade. Tradução dos artigos: Tomaz Tadeu da Silva. 3. ed; 2. riemp. Belo Horizonte, Autentica editora. 2016.

LOURO, G.L. Corpo, escola e identidade.Educação \& Realidade, Porto Alegre, v. 25, n. 2, p. 59-76, jul./dez. 2000.

LOURO, G.L. Gênero e sexualidade: pedagogias contemporâneas. Pro-Posições, v. 19, n. 2, p. 17-23, maio/ago. 2008.

SABAT, R. Gênero e sexualidade para consumo In: LOURO, G. L.; FELIPE, J.; GOELLNER, S. V. (org.). Corpo, gênero e sexualidade: um debate contemporâneo na educação. 9. ed. Petrópolis: Vozes, 2013.

SANT'ANNA, D. B. As infinitas descobertas do corpo. Cadernos pagu, Campinas, n.14, p. 235-249, 2000a.

SANT'ANNA, D. B. Descobrir o corpo: uma história sem fim. Educação e realidade, Porto Alegre, v.25, p. 49-58, jul./dez, 2000b.

SANT'ANNA, D. B. É possível realizar uma história do corpo? In: SOARES, Carmen Lúcia (org.). Corpo e História. 3.ed. São Paulo: Editora Autores Associados, 2006.

WEEKS. J. O corpo e a sexualidade. In: LOURO, G. L. (org.). O corpo educado: pedagogias da sexualidade. Tradução dos artigos: Tomaz Tadeu da Silva. 3. ed. 2. riemp. Belo Horizonte, Autentica editora. 2016. 
${ }^{i}$ Mestrando em Educação pelo Programa de Pós-Graduação em Educação da Universidade Estadual do Maranhão (PPGE) - Mestrado Profissional / UEMA; Graduado em Pedagogia Licenciatura pela Universidade Estadual do Maranhão (UEMA) e Membro do Grupo de Pesquisa Ensino de Ciências, Saúde e Sexualidade (GPENCEX/UEMA). E-mail: raysaoluis@ gmail.com. São Luís/Brasil - https://orcid.org/0000-0002-2097-0712

iiProfessor Adjunto do Departamento de Química e Biologia da Universidade Estadual do Maranhão (UEMA) e Líder do Grupo de Pesquisa Ensino de Ciências, Saúde e Sexualidade (GP-ENCEX/ UEMA); Doutor em Educação pela UNISINOS; Pós-Doutor em Educação pela UFRGS; Professor do Programa de Pós-Graduação em Educação da Universidade Estadual do Maranhão (PPGE - Mestrado Profissional / UEMA. São Luís/Brasil. E-mail: prof.jacksonronie.uema@gmail.com - https://orcid.org/0000-0001-9607-3674 